\title{
HPLC METHOD DEVELOPMENT FOR THE ANALYSIS OF BISOPROLOL IN COMBINED DOSAGE FORM CONTAINING BISOPROLOL AND ENALAPRIL AND IN VITRO DISSOLUTION STUDIED
}

\section{LILIYA LOGOYDA ${ }^{*}$, SERGIY KOVALENKO ${ }^{2}$, AHMED M. ABDEL-MEGIED ${ }^{3}$, IGOR ZHULKEVYCH ${ }^{4}$, IRYNA DRAPAK ${ }^{5}$, INNA DEMCHUK ${ }^{6}$, OLEH NETSYUK ${ }^{7}$}

1Pharmaceutical Chemistry Department, Pharmaceutical faculty, I. Horbachevsky Ternopil State Medical University, Ternopil City, Ukraine, ${ }^{2}$ Organic and Bioorganic Chemistry Department, Zaporizhzhya State Medical University, Zaporizhzhya, Ukraine, ${ }^{3}$ Pharmaceutical Analytical Chemistry Department, Faculty of Pharmacy Kafrelsheikh University, Kafrelshekh City, Egypt, ${ }^{4}$ Department of Oncology and Radiology, I. Ya. Horbachevsky Ternopil State Medical University, city Ternopil, Ukraine, ${ }^{5}$ General, Bioinorganic, Physical and Colloidal Chemistry Department, Danylo Halytsky Lviv National Medical University, Lviv City, Ukraine, ${ }^{6}$ Pharmaceutical, Organic and Bioorganic Chemistry Department, Danylo Halytsky Lviv National Medical University, Lviv City, Ukraine, ${ }^{7}$ L. Ya. Kovalchuk Department of Surgery, Urology, Minimally Invasive Surgery and Neurosurgery №1, I. Horbachevsky Ternopil State Medical University, Ternopil City, Ukraine Email: logojda@tdmu.edu.ua

Received: 05 Feb 2019, Revised and Accepted: 06 Apr 2019

\section{ABSTRACT}

Objective: A simple, rapid and reproducible HPLC method was developed for the determination of bisoprolol in experimental combined dosage forms containing bisoprolol and enalapril and for drug dissolution studies.

Methods: $\mathrm{A} \mathrm{C}_{18}$ column (Hi Qsil C18, $5 \mu \mathrm{m}, 4.6 \times 250 \mathrm{~mm}$ ) and a mobile phase methanol: phosphate buffer solution $(65: 35$, v/v) mixture were used for separation and quantification. Analyses were run at a flow rate of $1.0 \mathrm{ml} / \mathrm{min}$ and at ambient temperature. The injection volume was $300 \mu \mathrm{L}$ and the ultraviolet detector was set at $225 \mathrm{~nm}$. The method was validated as per ICH guidelines.

Results: Under these conditions, bisoprolol was eluted at $4.75 \mathrm{~min}$. Total run time was shorter than 6 min. A linear relationship between the concentration and the area of chromatographic peaks of bisoprolol in the range of $0.625 \mathrm{mg} / \mathrm{ml}-5.000 \mathrm{mg} / \mathrm{ml}(3.750 \mathrm{mg} / \mathrm{ml}$ at $\mathrm{pH} 1.2)$ has been established. In the medium with $\mathrm{pH} 1.2$ release of bisoprolol from tablets in $5 \mathrm{~min}$ is $38.42 \%$, and after $15 \mathrm{~min}-85.51 \%$, in medium with $\mathrm{pH} 4.5$ the release of bisoprolol from tablets in 5 min makes $59.78 \%$, and after 15 min-103.71\%; in a medium with pH 6.8, the release of bisoprolol from tablets in $5 \mathrm{~min}$ is $61.29 \%$, and after $15 \mathrm{~min}-85.90 \%$.

Conclusion: The developed method was applied successfully for quality control assay of bisoprolol in experimental tablets and in vitro dissolution studies.

Keywords: bisoprolol, high-performance liquid chromatography, validation, dissolution study

(C) 2019 The Authors. Published by Innovare Academic Sciences Pvt Ltd. This is an open-access article under the CC BY license (http://creativecommons.org/licenses/by/4.0/) DOI: http://dx.doi.org/10.22159/ijap.2019v11i3.32391

\section{INTRODUCTION}

A comparative dissolution kinetics test is a study whose purpose is to confirm the dissolution of the investigated drug in reference lens, in environments close to the gastrointestinal tract. Comparative dissolution kinetics test is used to confirm the equivalence of the drug, while the Dissolution test is used to determine the quality of the drug. Comparative dissolution kinetics test is used at all stages of the drug's life cycle. In the development of dosage form comparative dissolution kinetics test allows to assess the correctness of technological techniques, and thereby increase the probability of positive results for future studies of bioequivalence. In addition to routine quality control tests, comparative dissolution tests have been used to waive bioequivalence requirements (biowaivers) for lower strengths of a dosage form [1].

When planning the design of the experiment, it is necessary to gather information on the structure of the API molecule, the acidbasic properties, solubility, stability in dissolution media, the class according to the biopharmaceutical classification system (BSC). For the quantitative determination of the concentration of API that has been converted into a solution, developed and validated a method is very important. Almost for comparative dissolution kinetics test has been used spectrophotometry and HPLC. Among the disadvantages of spectrophotometry, low selectivity, low sensitivity and relatively high variability of the results of the analysis can be noted. Therefore, the advantage is provided by HPLC.

There is an HPLC method described for determination of bisoprolol in pharmaceutical preparations [2-5]. However, those methods are not developed for the determination of bisoprolol in dissolution studies while the dissolution profile of bisoprolol and enalapril from the combination drug product has not hitherto been reported in the literature. In order to elucidate the dissolution profiles bisoprolol and enalapril, a validated HPLC method is required for determination of bisoprolol from tablets in dissolution matrix.

Bisoprolol is a medicines most commonly used for heart diseases, the beta blocker family of medications and is of the $\beta 1$ selective type Bisoprolol is beneficial in the treatment for high blood pressure (hypertension), reduced blood flow to the heart (cardiac ischemia); congestive heart failure, and preventive treatment before and primary treatment after heart attacks decreasing the chances of recurrence. The chemical name is 1-[4-[[2-(1-Methylethoxy) ethoxy]methyl]phenoxy]-3-[(1-methylethyl)amino]-2-propanol. Its structure is shown in fig. 1.

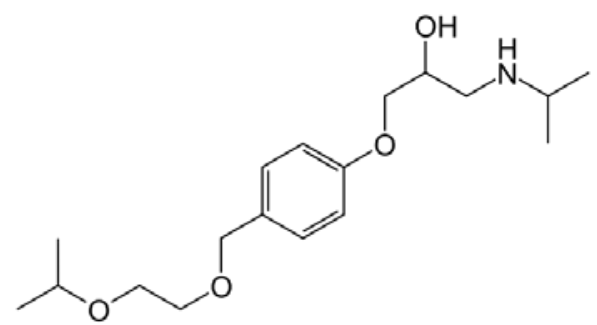

Fig. 1: The chemical structures of of bisoprolo

Therefore, the aim of this study was to develop and validate an efficient HPLC method for determination of bisoprolol and to introduce the dissolution profiles of tablets which contain bisoprolol and enalapril. Moreover, this new method could also be used for the 
routine analysis of bisoprolol in pharmaceutical dosage forms, provided it is completely validated and rapid. The present method was simple, sensitive, and selective and developed with low-cost solvent in the mobile phase and simple standard preparation and separation were done at shorter run time and all parameters were validated according to ICH guidelines [6].

In vitro dissolution of bisoprolol containing tablets were performed to validate the suitability of the proposed method.

\section{MATERIALS AND METHODS}

\section{Chemicals}

Standard bisoprolol and enalapril were supplied by Refik Saydam National Public Health Agency. Methanol and phosphate buffer solution were of HPLC grade from Merck (Darmstadt, Germany) and all other reagents were analytical grade. Water obtained from the Milli-Q water system (Barnstead, USA) was used for the preparation of buffer and other aqueous solutions. Experimental tablets containing $5 \mathrm{mg}$ of enalapril and $2.5 \mathrm{mg}$ of bisoprolol were developed by Prof. Kachrimanis Kyriakos (Department of Pharmaceutical Technology, Aristotle University of Thessaloniki, School of Pharmacy, Thessaloniki, Greece).

\section{Preparation of strock solution}

Standard stock solutions of bisoprolol were prepared separately by dissolving $50 \mu \mathrm{g}$ of bisoprolol fumarate in $50 \mathrm{ml}$ appropriate solvent. These solutions were prepared freshly every week, during method development and application period.

\section{Preparation of calibration standards}

Calibration standards for bisoprolol (as fumarate salt) (1.25, 2.0, 3.0, $4.0,10.0,20.0,30.0,40$ and $50.0 \mu \mathrm{g} \mathrm{ml}-1$ ) were daily prepared from standard stock solutions by appropriate dilution processes using mobile phase.

\section{Instrumentation}

The HPLC system consisted of Agilent 1260. A C18 column (Hi Qsil C18, 5 $\mu \mathrm{m}, 4.6 \times 250 \mathrm{~mm}$ ) was used for separation and quantification. The mobile phase consisted of methanol: phosphate buffer solution $65: 35$, $\mathrm{v} / \mathrm{v}$ ) and was filtered through a $0.45 \mu \mathrm{m}$ filter and degassed before use. The injection volume was $300 \mu \mathrm{L}$ and the ultraviolet detector was set at $225 \mathrm{~nm}$. Analyses were run at a flow rate of $1.0 \mathrm{ml} / \mathrm{min}$ at an ambient temperature $\left(25^{\circ} \mathrm{C}\right)$. The peak area was integrated automatically by using Empower ${ }^{\circledR}$ software. Under these conditions, bisoprolol was eluted at $4.75 \mathrm{~min}$. Total run time was shorter than $6 \mathrm{~min}$.

\section{In vitro dissolution studies}

In vitro dissolution of twelve tablets containing bisoprolol and enalapril was performed using buffer solutions ( $\mathrm{pH} 1.2 ; 4.5 ; 6.8)$ as the dissolution media at $50 \mathrm{rpm}$ using an USP Apparatus II. The dissolution study was carried out in a $900 \mathrm{ml}$ volume of buffer solution at $37{ }^{\circ} \mathrm{C}( \pm 0.5)$ using the paddle method. One $\mathrm{ml}$ of sample was withdrawn and replaced with fresh dissolution medium at the time intervals of 5, 15, 30, $45 \mathrm{~min}$. The concentrations of bisoprolol in samples were determined by the proposed HPLC method.

According to the FDA Guidance (Qui, Xu 2007) not less than 85\% of the active ingredients of the labeled claim should be dissolved within 30 min.

\section{Analytical method validation}

Once the chromatographic and the experimental conditions were established, the method was validated by the determination of the following parameters such linearity range, sensitivity, repeatability, precision, accuracy, and specificity, as per ICH Q2 (R1) guidelines [6-8].

\section{System suitability parameters}

The chromatographic systems used for analysis must pass system suitability before going to start the experiment. At first HPLC system is stabilized for forty minutes. Inject blank preparation (single injection) and standard preparation (six replicates) and record the chromatograms to evaluate the system suitability parameters such as tailing factor (NMT 1.5), theoretical plate count (NLT 3000) and retention time. The \% RSD for the peak area of six replicate injections of bisoprolol fumarate standard NMT 2.0. The parameters such as tailing factor, \% RSD and theoretical plates were studied.

\section{Linearity}

A standard stock solution of the bisoprolol fumarate $(0.1 \mathrm{mg} / \mathrm{ml})$ was prepared with the same solvent. To study the linearity range of drugs, serial dilutions were made from a standard stock solution in the range of $25-200 \%$ of the nominal concentrations of bisoprolol in the test solution.

\section{Specificity}

Specificity of an analytical method is its ability to measure accurately and specifically the analyte of interest without interference from placebo and degradation products. The specificity of the method was established by injecting blank, placebo and standard solution in triplicate and recording the chromatograms.

\section{Precision}

The precision of the method was determined by repeatability (intraday) and intermediate precision (interday). Repeatability was determined by performing repeated analysis of the same working solution of bisoprolol fumarate on the same day, under the same experimental conditions. The intermediate precision of the method was assessed by carrying out the analysis on different days and also by another analyst performing the analysis in the same laboratory (between-analysts).

\section{Accuracy}

The accuracy of a method is defined as the closeness of a measured value to the true value. The recovery studies were carried out at $25-$ $200 \%$ of the target level in the tablet in triplicate each in the presence of placebo.

\section{RESULTS AND DISCUSSION}

\section{Optimization of chromatographic conditions}

Literature survey revealed, RP-HPLC method was developed for determination of bisoprolol fumarate in tablets. The mobile phase was a mixture of methanol: acetonitrile: $45 \mathrm{mmol}$ potassium dihydrogen phosphate buffer (30:25:45) at $\mathrm{pH} 3.0$ and $0.3 \mathrm{ml} / \mathrm{min}$. The stationary phase used was a SB-C18Nucleosil column $(125 \times 4 \mathrm{~mm})$. The UV detection was performed at $225 \mathrm{~nm}$. The method was validated as tar as linearity, limit of detection, limit of quantification, precision, accuracy, recovery and system suitability. The calibration graph was linear in the concentration range $0.3-10 \mu \mathrm{g} / \mathrm{ml}$. The assay proved to be sensitive, specific and reproducible. The method was applied for the determination of bisoprolol in tablets and in a bioequivalence study [2]. However, this method is for analysis of bisoprolol im monomedicine and this method is not developed for the determination of bisoprolol in dissolution studies while the dissolution profile of bisoprolol and enalapril from the combination drug product has not hitherto been reported in the literature. In order to elucidate the dissolution profiles bisoprolol and enalapril, a validated HPLC method is required for determination of bisoprolol from tablets in dissolution matrix.

In the present study due to the relative apolar properties of bisoprolol and enalapril, a reversed phase HPLC system was used to analyze both compounds with a sufficient separation and fine peak shapes within a short analysis time. The chromatographic separation was done with various trails using different conditions. Based on theoretical plates, peak shape and back pressure, the column was selected. Finally, the chromatographic separation was carried out using C18 column (Hi Qsil C18, $5 \mu \mathrm{m}, 4.6 \times 250 \mathrm{~mm}$ ) by trying various mobile phase [9-29]. After the initial experiments, the optimum conditions were found to be the mobile phase of methanol: phosphate buffer solution $(65: 35, \mathrm{v} / \mathrm{v})$ mixture pumped at 1.0 $\mathrm{ml} / \mathrm{min}$ flow rate and $225 \mathrm{~nm}$ UV detection wavelength, which ensured the identification of both APIs insufficient intensity. Under the optimum conditions, bisoprolol was eluted at $4.75 \mathrm{~min}$. The optimized chromatographic conditions are tabulated in table 1. 
Table 1: Optimized chromatographic conditions and system suitability parameters

\begin{tabular}{ll}
\hline Parameter & Chromatographic conditions \\
\hline Instrument & Agilent 1260 \\
Column & Hi Qsil C18,5 $\mu \mathrm{m}, 4.6 \times 250 \mathrm{~mm}$ \\
Mobile phase & Methanol: phosphate buffer solution $(65: 35, \mathrm{v} / \mathrm{v})$ \\
Flow rate & $1.0 \mathrm{ml} / \mathrm{min}$ \\
Detection wavelength & $\mathrm{UV}$ at $225 \mathrm{~nm}$ \\
Runtime & $6 \mathrm{~min}$ \\
Column temperature & $25^{\circ} \mathrm{C}$ \\
Volume of the injection loop & $300 \mu \mathrm{l}$ \\
Retention time (bisoprolol) & $4.75 \mathrm{~min}$ \\
\hline
\end{tabular}

Representative chromatogram of bisoprolol fumarate in tablets containing bisoprolol and enalapril is presented in fig. 2 .

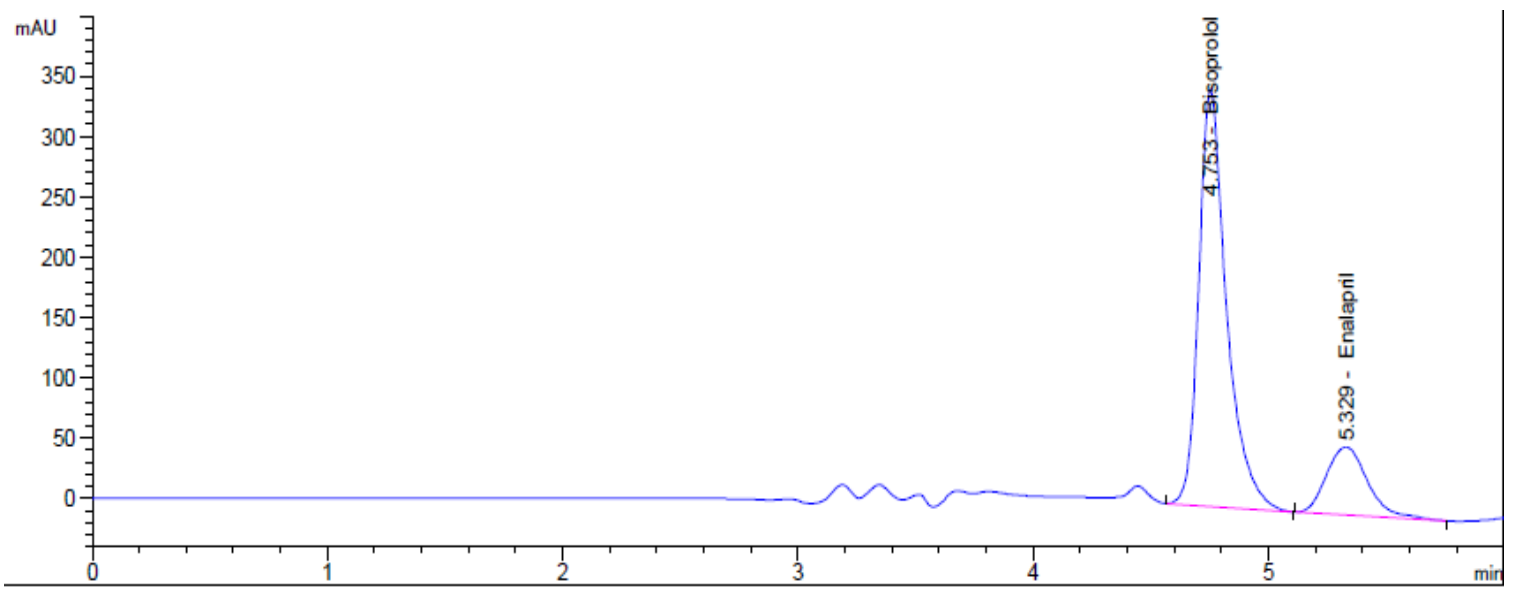

Fig. 2: Representative chromatogram of bisoprolol fumarate

\section{Method validation}

The proposed method was validated as to linearity range, sensitivity, repeatability, precision, accuracy, and specificity according to the ICH guidelines [6].

\section{System suitability}

A suitability test was applied to the chromatograms taken under optimum conditions to check various parameters such as column efficiency (plates), peak tailing, retention factor, and resolution. Suitable resolution $(>2)$ and column efficiency $(>1500$ for both compounds) were achieved for the analysis method. The peak symmetries for both compounds were $<1.2$, whereas the capacity factors were $>1.5$. The analysis time was shorter than $6 \mathrm{~min}$.

\section{Linearity range}

Calibration curve representing the relation between the concentrations of drugs versus the peak area were constructed. In triplicate run from which the linear regression equation was calculated. The results obtained were processed by the least squares method. The correlation coefficient of bisoprolol fumarate $\mathrm{r}^{2}$ was noted more than 0.9991 which states that the method was good linear to the concentration versus peak area responses. Results indicate high sensitivity of the proposed HPLC method. The calibration graph of bisoprolol fumarate is presented in fig. 3-5 and characteristics of the linear dependence of bisoprolol fumarate are listed in table 1.

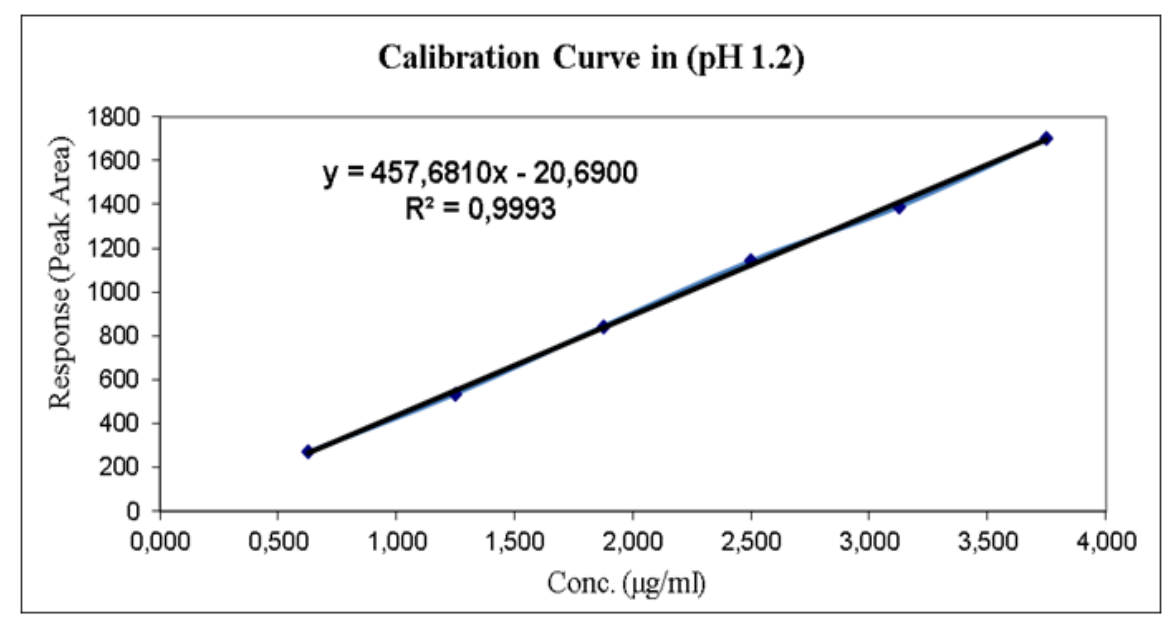

Fig. 3: Linearity on profils of dissolution test at pH 1.2 


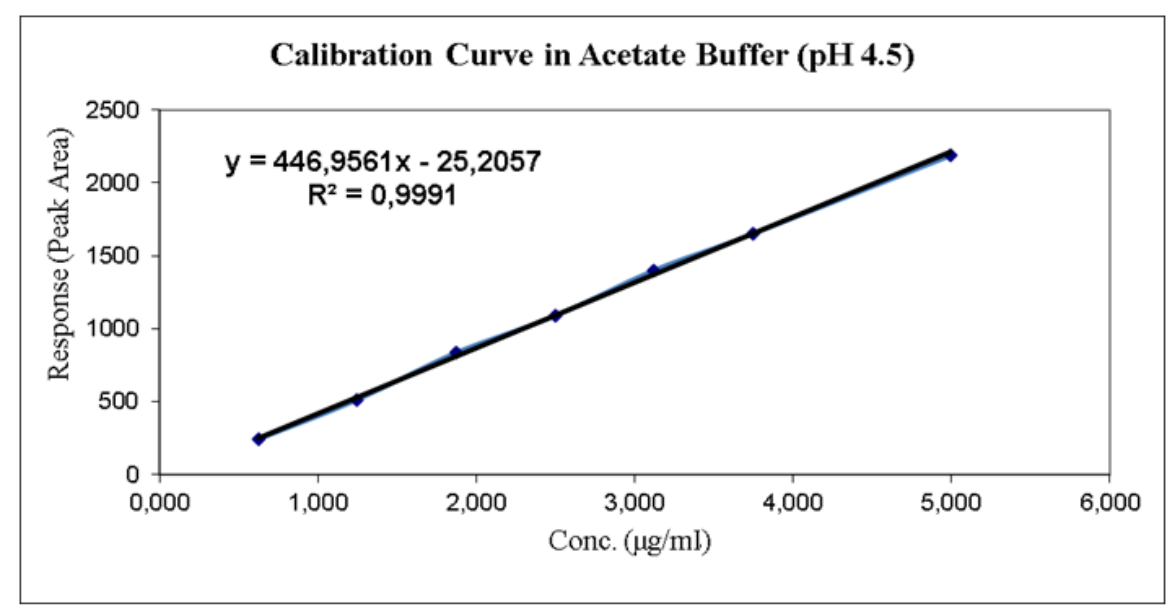

Fig. 4: Linearity on profils of dissolution test at pH 4.5

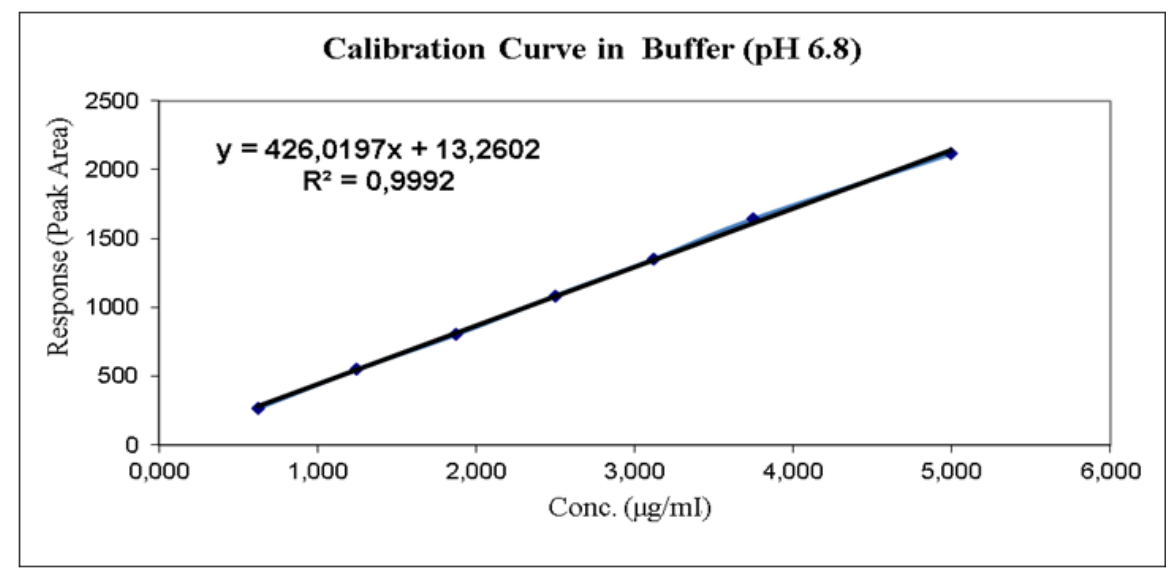

Fig. 5: Linearity on profils of dissolution test at pH 6.8

Table 2: Characteristics of the linear dependence of bisoprolol fumarate

\begin{tabular}{lllll}
\hline $\mathbf{p H}$ & Concentration range $(\mathbf{m g} / \mathbf{m l})$ & Regression equation & $\mathbf{R}^{\mathbf{2}}$ & Compliance with eligibility criteria \\
\hline 1.2 & $0.625-3.750$ & $\mathrm{y}=457.6180 \mathrm{x}-20.6900$ & 0.9993 & Corresponds \\
4.5 & $0.625-5.000$ & $\mathrm{y}=446.9561 \mathrm{x}-25.2057$ & 0.9991 & Corresponds \\
6.8 & $0.625-5.000$ & $\mathrm{y}=426.0197 \mathrm{x}+13.2602$ & 0.9992 & Corresponds \\
\hline
\end{tabular}

A linear relationship between the concentration and the area of chromatographic peaks of bisoprolol in the range of $0.625 \mathrm{mg} / \mathrm{ml}$ $5.000 \mathrm{mg} / \mathrm{ml}(3.750 \mathrm{mg} / \mathrm{ml}$ at $\mathrm{pH} \mathrm{1.2)}$ was established (table 2). Requirements for linear dependency parameters are performed in this case throughout the range of application of the technique. Linearity studies were conducted in a wide range of concentrations (25-200\% at $\mathrm{pH} 4.5$ and $6.8,25-150 \%$ at $\mathrm{pH} 1.2)$

\section{Specificity}

Specificity was carried out by evaluation of blank, standard and sample injections. The resultant chromatograms of blank, standard and sample were compared, the correlation was good between standard and sample and no interference of excipients in blank with drug was observed. The specificity results are tabulated in table 3.

Table 3: Specificity study

\begin{tabular}{ll}
\hline Name of the solution & Retention time (tR) min \\
\hline mobile phase & No peaks \\
placebo & No peaks \\
bisoprolol fumarate & 4.75 \\
Another API (enalapril) & 5.33 \\
\hline
\end{tabular}

The representative chromatograms (fig. 6-11) show no other peaks in retention time of bisoprolol and enalapril and retention times did not change. In addition, when the solution prepared from the blank tablet was injected into the HPLC system, no co-eluting peaks were obtained at the retention time of bisoprolol and enalapril. Based on these results, the proposed methods can be considered selective. 


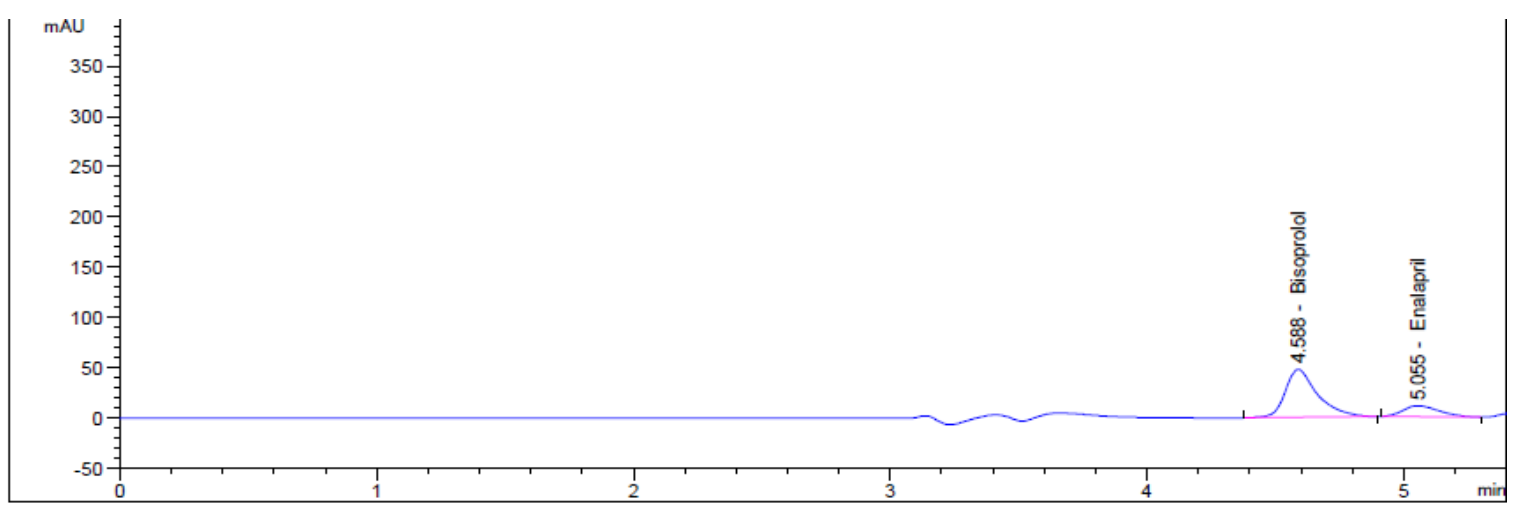

Fig. 6: Representative chromatogram of bisoprolol fumarate under conditions of study of dissolution kinetics at pH 1.2 (timing-15 min)

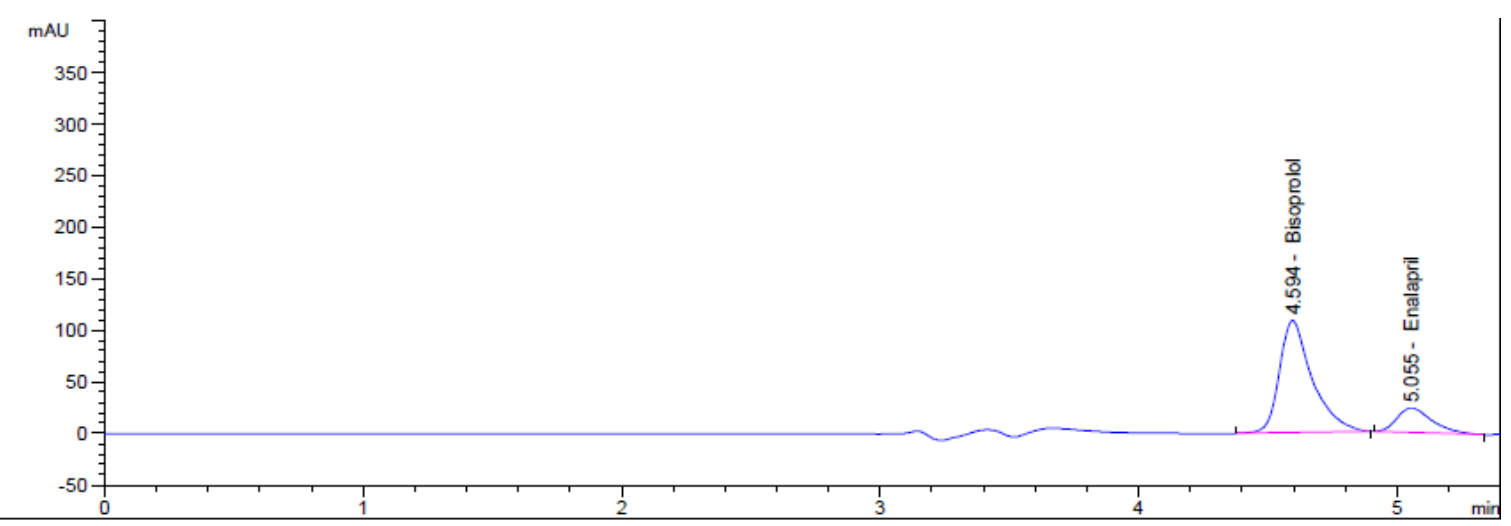

Fig. 7: Representative chromatogram of bisoprolol fumarate under conditions of study of dissolution kinetics at pH 1.2 (timing-30 min)

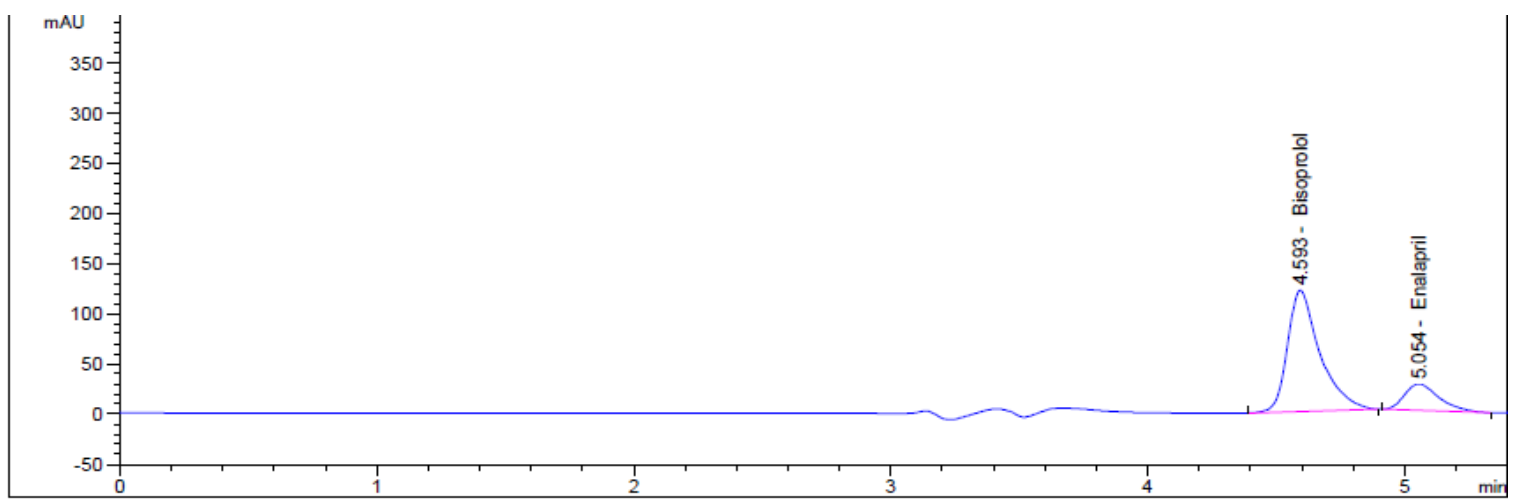

Fig. 8: Representative chromatogram of bisoprolol fumarate under conditions of study of dissolution kinetics at pH 4.5 (timing-15 min)

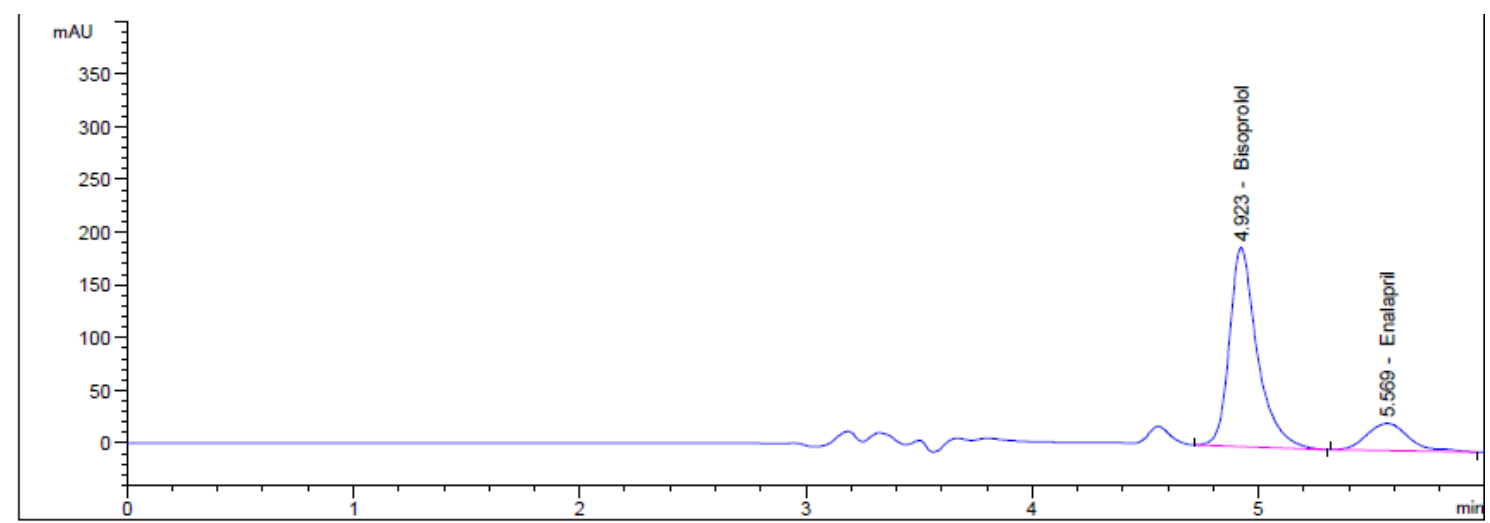

Fig. 9: Representative chromatogram of bisoprolol fumarate under conditions of study of dissolution kinetics at pH 4.5 (timing-30 min) 


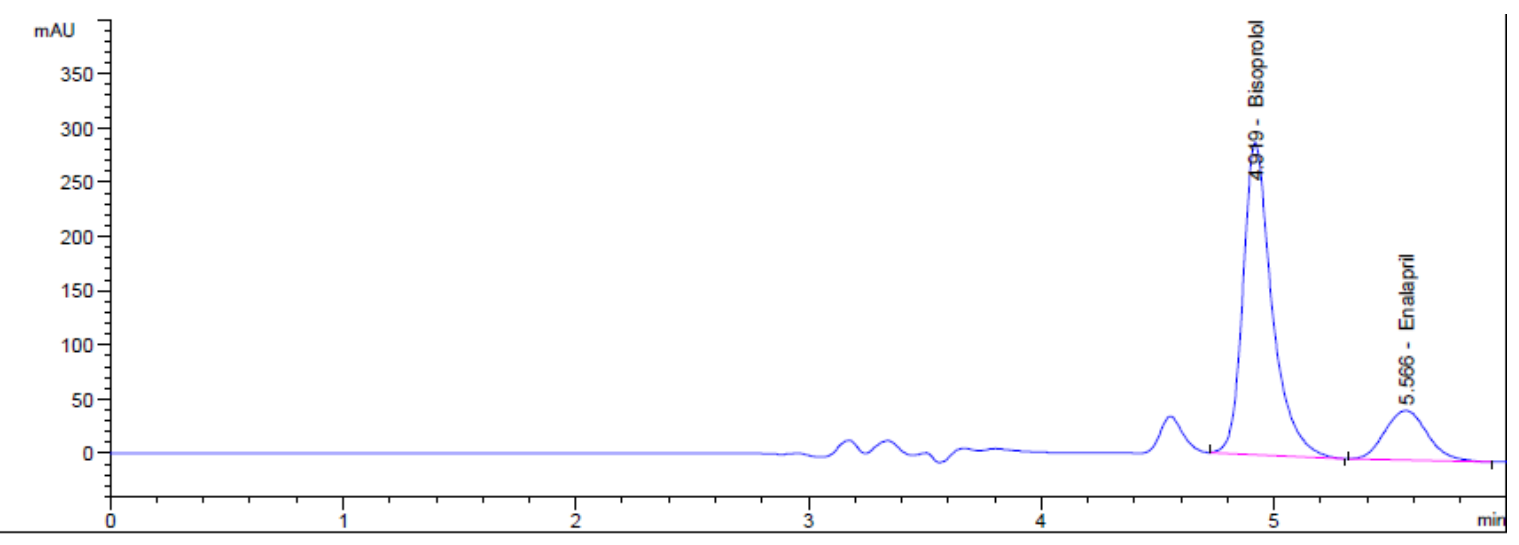

Fig. 10: Representative chromatogram of bisoprolol fumarate under conditions of study of dissolution kinetics at pH 6.8 (timing-15 min)

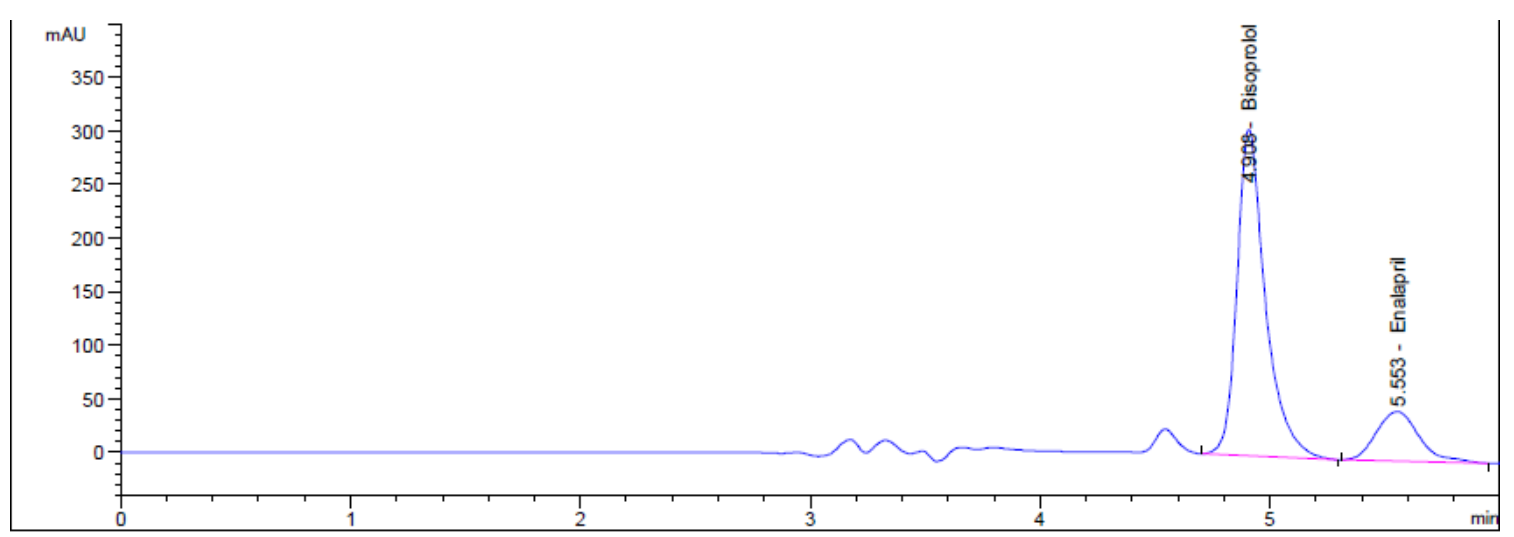

Fig. 11: Representative chromatogram of bisoprolol fumarate under conditions of study of dissolution kinetics at pH 6.8 (timing-30 min)

Commonly used tablet excipients did not interfere with this method. It shows that the method is specific.

\section{Accuracy and precision}

System precision is shown in table 4. Intra-day and inter-day \% RSD values lower than $2 \%$ clearly assuring that this method was found to be fairly precise and reproducible (table 5). Regarding accuracy, a known amount of the standard drug was added to the fixed amount of preanalyzed sample solution. \% recovery was calculated by comparing the area before and after the addition of the standard drug. The standard addition method was performed at 25-200 \% levels concentrations. The high value of recoveries obtained for bisoprolol indicates that the proposed method was found to be accurate.

\section{In vitro dissolution studies}

The average percentage of drugs released as detected by the proposed HPLC method after in vitro dissolution of tablets containing combination drug product are depicted in fig. 12-14.

Table 4: Results of system precision $(n=5)$

\begin{tabular}{lllll}
\hline Sample & Concentration $(\boldsymbol{\mu g} / \mathbf{m l})$ & Peak area & Injection no. & RSD, \% \\
\hline Bisoprolol & 0.1 & 1086,213 & 1 & 0.07 \\
& & 1086,486 & 2 & \\
& & 1085,791 & 3 & \\
& 1084,526 & 4 & \\
\hline
\end{tabular}

$\mathrm{n}$ is number of determinations, RSD is relative standard deviation

Table 5: Intra-day and Inter-day precision data of bisoprolol fumarate (n=3)

\begin{tabular}{lllll}
\hline Day & Intra-day precision & \multicolumn{3}{l}{ Inter-day precision } \\
\cline { 2 - 5 } & Mean & RSD \% & Mean & RSD \% \\
\hline 1 & 99.42 & 0.211 & 100.18 & 0.264 \\
2 & 100.11 & 0.347 & 99.93 & 0.230 \\
3 & 100.62 & 0.246 & 100.45 & 0.381 \\
\hline
\end{tabular}

$\mathrm{n}$ is number of determinations, RSD is relative standard deviation 


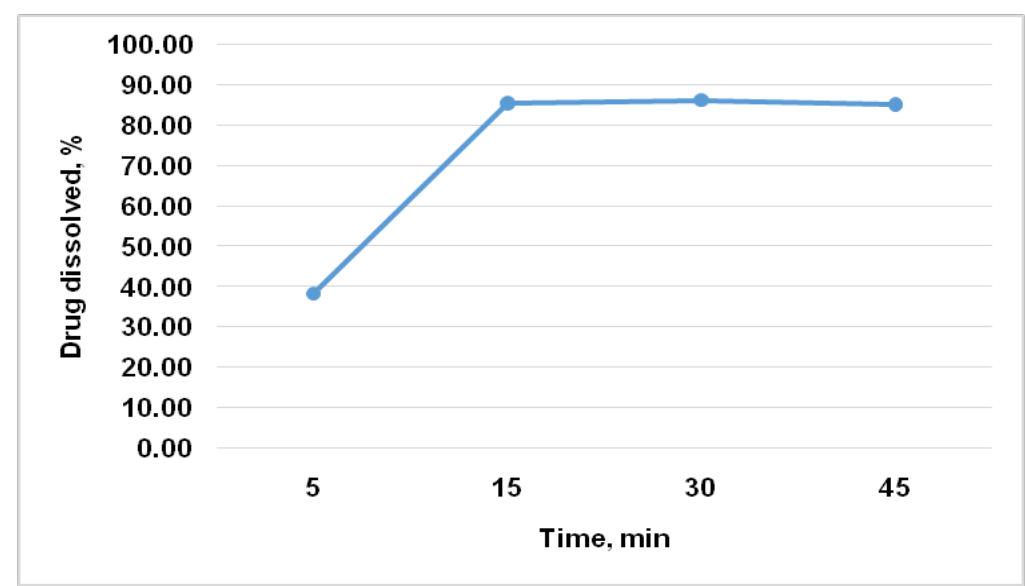

Fig. 12: In vitro dissolution profiles of bisoprolol at $\mathrm{pH} 1.2$ mean $\pm S D, n=3$

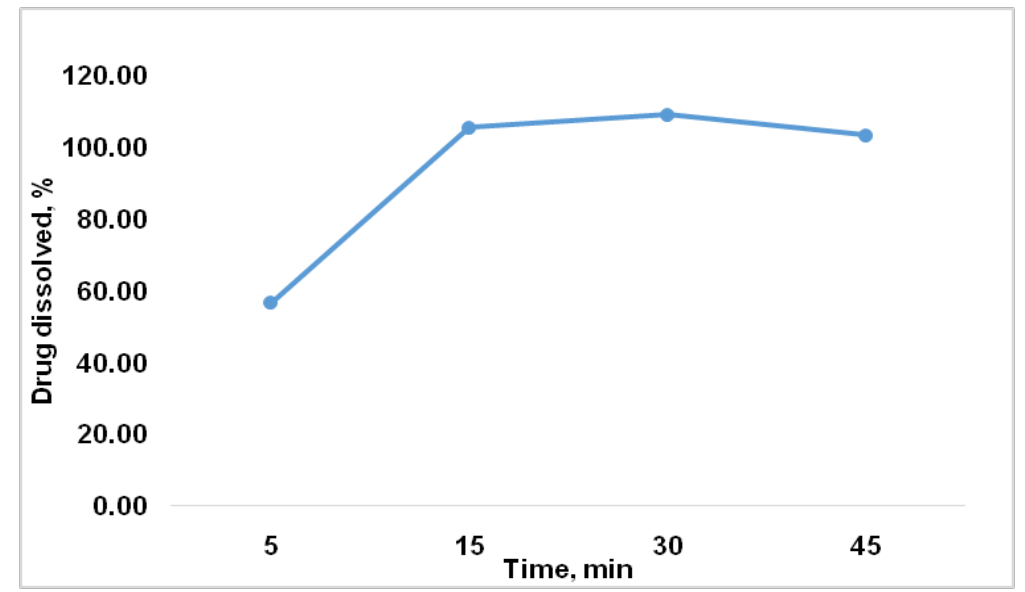

Fig. 13: In vitro dissolution profiles of bisoprolol at $\mathrm{pH} 4.5$ mean $\pm \mathrm{SD}, \mathrm{n}=3$

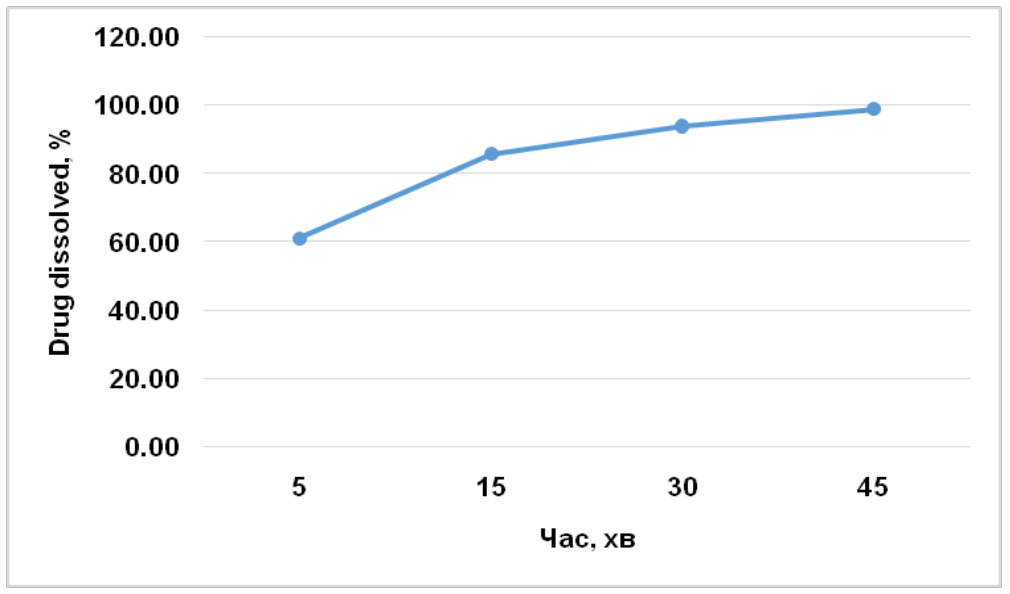

Fig. 14: In vitro dissolution profiles of bisoprolol at $\mathrm{pH} 6.8$ mean $\pm \mathrm{SD}, \mathrm{n}=3$

The point « 15 min» is critical and decisive. Medicine is considered very quick soluble when at least $85 \%$ of the active substance dissolves in 15 min, quickly soluble-when at least $85 \%$ of the active substance dissolves in $30 \mathrm{~min}$.

Dissolution testing should be carried out under mild test conditions, basket method at 50/100 rpm or paddle method at 50/75 rpm, at 15minute intervals, to generate a dissolution profile. For rapidly-dissolving products, generation of an adequate profile sampling at 5-or 10-minute intervals may be necessary. For highly soluble and rapidly dissolving drug products (BCS classes 1 and 3), a single-point dissolution test specification of $\mathrm{NLT} 85 \%(\mathrm{Q}=80 \%)$ in $60 \mathrm{~min}$ or less is sufficient as a routine quality control test for batch-to-batch uniformity.

As can be seen from fig. 12-14, in the medium with $\mathrm{pH} 1.2$ release of bisoprolol from tablets in $5 \mathrm{~min}$ is $38.42 \%$, and after $15 \mathrm{~min}-85.51 \%$, in medium with $\mathrm{pH} 4.5$ the release of bisoprolol from tablets in $5 \mathrm{~min}$ makes 59.78\%, and after 15 min-103.71\%; in a medium with $\mathrm{pH}$ 6.8, the 
release of bisoprolol from tablets in $5 \mathrm{~min}$ is $61.29 \%$, and after $15 \mathrm{~min}$ $85.90 \%$. The results indicated that the drug release from the matrix tablets followed zero order kinetics. To evaluate the drug release mechanism from the matrix tablets plots of percent drug released verses square root of time as per Higuchi's equation were constructed. These plots were found to be linear with all the tablets with correlation coefficient values in the range 0.9991 to 0.9993 indicating that the drug release from the tablet was controlled. The dissolution pattern complies with the FDA standards, indicating the suitability of the proposed method for the dissolution study of bisoprolol.

Compared to the previous method [2], this method is selective, simple, sensitive, and separation was done at shorter run time and in the presence of another API in tablets (enalapril).

The studies conducted have shown that bisoprolol can be referred to class I of BSC, i.e. substances with a high biopharmaceutical solubility. It will allow conducting comparative studies in vitro to confirm the equivalence of drugs.

\section{CONCLUSION}

The RP-HPLC method for estimation of bisoprolol was found to be simple, sensitive, precise and accurate. The present study of method development and method validation was as per ICH guidelines, and it meets the specific acceptance criteria. Based on the results, it can be concluded that there is no other co-eluting peak with the main peaks and that the method is specific for estimation of bisoprolol. The proposed method has linear response in the stated range and is accurate and precise. The developed method can also be conveniently adopted for dissolution testing of tablets containing bisoprolol. This method can help research studies, quality control and routine analysis, where economy and time were essential.

\section{ACKNOWLEDGMENT}

The authors are thankful to Prof. Kachrimanis Kyriakos (Department of Pharmaceutical Technology, Aristotle University of Thessaloniki, School of Pharmacy, Thessaloniki, Greece) for development experimental tablets.

\section{AUTHORS CONTRIBUTIONS}

All the authors have contributed equally

\section{CONFLICT OF INTERESTS}

The authors declare no conflict of interest

\section{REFERENCES}

1. https://www.fda.gov/downloads/drugs/guidances/ucm07023 7.pdf [Last accessed on 01 Jan 2019]

2. Panainte AD. A HPLC method for the determination of bisoprolol in tablets and its application to a bioequivalence study. Revista De Chimie 2015;66:1791-5.

3. Arjun G. A simple HPLC method for quantitation of bisoprolol fumarate in tablet dosage form. Indian Drugs 2009;46:39-42.

4. Yuliya Kondratova, Liliya Logoyda, Yuliia Voloshko, Ahmed Abdel-Megied, Dmytro Korobko, Yuriy Soroka. Development and validation of HPLC-DAD method for the determination of bisoprolol in tablet dosage forms. Int J Appl Pharm 2017;9:54-9.

5. Kondratova Y, Adebayo T, Logoyda L, Korobko D, Berdey I, Kuchmerovska T. Development of the methodology of the chromatographic determination of amlodipine in medicines. Int J Res Ayurveda Pharm 2016;7:32-5.

6. Guidelines for validation of Analytical Procedures, Q2 (R1), ICH; 2005.

7. Yazdanian M, Briggs $\mathrm{K}$, Jankovsky $\mathrm{C}$, Hawi A. The "high solubility" definition of the current FDA guidance on biopharmaceutical classification system may be too strict for acidic drugs. Pharm Res 2004;21:293-9.

8. Srinivasan B, Kolli AR, Esch MB, Abaci HE, Shuler ML, Hickman JJ. TEER measurement techniques for in vitro barrier model systems. J Lab Autom 2015;20:107-26.

9. Liliya Logoyda, Yuliya Kondratova, Dmytro Korobko, Yuriy Soroka. Development of UHPLC method for the determination of captopril in pharmaceutical dosage forms. Asian J Pharm Clin Res 2017;10:308-10.
10. Liliya Logoyda, Ahmed M Abdel-Megied, Yuliya Kondratova, Olena Trofimenko, Dmytro Korobko, Iryna Dakhym. Development and validation of HPLC method for the simultaneous determination of enalapril maleate in present of their impurities: application to tablet analysis. Int J Appl Pharm 2018;10:98-102.

11. Liliya L, Dmytro K, Olena S, Ihor B, Tamara K. Development of methodology for identification of captopril in medicines. Asian J Pharm 2016;10:168-71.

12. Logoyda L, Korobko D, Saprun S, Zarivna N. Development of methods for the chromatographic identification of active pharmaceutical ingredient from group of angiotensinconverting enzyme inhibitors in pharmaceuticals. Int J Green Pharm 2017;11 Suppl:737-41.

13. Liliya Logoyda, Dmytro Korobko, Iryna Ivanusa, Kovalenko Serhii. Development of the methodology of the chromatographic determination of nifedipine in medicines. Asian J Pharm Clin Res 2017;10:149-52.

14. Logoyda Liliya, Korobko Dmutro, Saprun Stanislav. Development of methods for identification of calcium channel blockers in medicines. Int J Res Ayurveda Pharm 2016;7:88-91.

15. Olgya Polyauk, Liliya Logoyda. The investigation of conditions of API from group of calcium channel blockers extraction by organic solvents by using high-performance liquid chromatography as method assay. Asian J Pharm Clin Res 2017;10:354-6.

16. Kondratova Y, Adebayo T, Logoyda L, Korobko D, Berdey I, Kuchmerovska T. Development of the methodology of the chromatographic determination of amlodipine in medicines. Int J Res Ayurveda Pharm 2016; 7:32-5.

17. Logoyda L, Abdel Megied AM, Kondratova Y, Trofimenko O, Korobko D, Dakhym I. Development and validation of HPLC method for the simultaneous determination of enalapril maleate in present of their impurities: application to tablet analysis. Int J Appl Pharm 2018;10:98-102.

18. Liliya Logoyda, Dmytro Korobko, Oleksandra Oleshchuk, Taras Proniv, Mariya Dmutriv. A HPLC MS/MS method development and validation for the simultaneous determination of bisoprolol and enalapril in the present of enalaprilat in human plasma. Int J Appl Pharm 2018;10:31-40.

19. Logoyda L, Mykhalkiv M, Polyauk O, Zarivna N, Soroka Y, Demydiak 0. Ultra-high-performance liquid chromatography as assay method for the investigation of conditions of captopril extraction by organic solvents. Asian J Pharma 2018;12 Suppl:111-4.

20. Mykhalkiv M, Logoyda L, Polyauk O, Zarivna N, Soroka Y, Ryabokon S, et al. HPLC as assay method for the investigation of conditions of bisoprolol extraction by organic solvents. Int J Green Pharm 2018;12 Suppl:276-9.

21. Liliya Logoyda. Bioanalytical method development and validation from the simultaneous determination of verapamil and enalapril in the present of enalaprilat by HPLC MS/MS. Int J Appl Pharm 2018;10:19-27.

22. Liliya Logoyda. Quantitative determination of amlodipine from caco-2 cell monolayers by high-performance liquid chromatography-mass spectrometry/mass spectrometry. Asian J Pharm Clin Res 2018;11:204-7.

23. Yuryeva O, Kondratova Y, Logoyda L. Development of highperformance liquid chromatography method for the simultaneous analysis of amlodipine and valsartan in combined dosage form and in vitro dissolution studies. Asian J Pharm Clin Res 2018;11:200-4.

24. Mykhalkiv M, Logoyda L, Ivanusa I, Soroka Y, Yakubishyna I. High-performance liquid chromatography as assay method for the investigation of conditions of enalapril maleate extraction by organic solvents. Int J Green Pharm 2018;12:62-5.

25. Logoyda L, Kondratova Y, Korobko D, Susla O, Soroka Y, Tsytsiura R, et al. Youden's test of the chromatographic determination of captopril in pharmaceuticals. Int J Green Pharm 2017;11:188-91.

26. Liliya Logoyda. A HPLC-MS/MS method development and validation for the simultaneous determination of nifedipine and enalapril in human plasma. Int J Appl Pharm 2018;10:35-42. 
27. Liliya Logoyda. A high-performance liquid chromatographymass spectrometry method development for the quantitative determination of enalapril maleate from caco-2 cell monolayers. Asian J Pharm Clin Res 2018;11:89-92.

28. Logoyda L, Korobko D. A high-performance liquid chromatography-mass spectrometry/mass spectrometry method development for the quantitative determination of bisoprolol from caco-2 cell monolayers Asian J Pharm Clin Res 2018;11:386-9.

29. Shohin IE, Ramenskaya GV, Vasilenko GF, Malashenko EA. In vitro dissolution kinetics of amlodipine tablets marketed in russia under biowaiver conditions. Dissolution Technologies (august); 2010. p. 20-2. 